\title{
Effect of corrosion and fatigue on the remaining life of structures and its implication to additive manufacturing
}

\author{
D. Peng, R. Jones \\ Centre of Expertise for Structural Mechanics, Department of Mechanical and Aerospace \\ Engineering, Monash University, P.O. Box 31, Monash University, Victoria, 3800, Australia.
}

\section{F. Berto, S.M.J. Razavi}

Department of Mechanical and Industrial Engineering, Norwegian University of Science and Technology (NTNU), Trondheim 7491, Norway

\begin{abstract}
This paper investigates the combined effect of corrosion and fatigue on the growth of cracks that arise from natural corrosion in steel bridges. It is shown that if these two effects need to be simultaneously analyzed. If not, then the resulting life is not conservative. Consequently, to enable a better understanding of the remaining life of steel bridges this paper presents a simple methodology for performing this coupled analysis. The implication of this study to additively manufactured Ti-6Al-4V is also discussed.
\end{abstract}

KEYWORDS. Steel bridges; Corrosion; Fatigue crack growth; Remaining life.

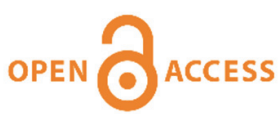

Citation: Peng., D., Jones, R., Berto, F., Razavi, S.M.J., Effect of corrosion and fatigue on the remaining life of structures and its implication to additive manufacturing, Frattura ed Integrità Strutturale, 45 (2018) 3344.

Received: 02.05.2018

Accepted: 25.05.2018

Published: 01.07.2018

Copyright: (C) 2018 This is an open access article under the terms of the CC-BY 4.0, which permits unrestricted use, distribution, and reproduction in any medium, provided the original author and source are credited.

\section{INTRODUCTION}

I t has long been known that the corrosion of steel bridges can have a marked effect on structural integrity. Indeed, the collapse of the I35W bridge in Minneapolis, USA led US Rep. Michael Conway (R-TX11) to introduce the Bridge Life Extension Act of 2008. Transportation for America subsequently conducted an analysis of the US National Bridge Inventory [1] and reported that one in nine U.S. bridges were rated as being structurally deficient. In this context it should be noted that for steel bridges the primary problems essentially result from either corrosion due to exposure of the steel to atmospheric conditions and/or from small non-detectable initial material discontinuities [2]. As a result, the US National Cooperative Highway Research Program, NCHRP Synthesis study [2] highlighted the need to develop advanced fatigue life calculation procedures that were capable of accounting for non-visible cracks in steel bridges. Indeed, the need to be able to account for small sub $\mathrm{mm}$ initial defects is reinforced in the US Federal Highway Administration Steel Bridge Design Handbook [3] where it was noted that crack growth essentially starts from day one and that the majority of the life of steel 
bridges is consumed in growing to a size where a crack can be detected. As explained in [4] this observation coincides with that seen in the growth of cracks in operational aircraft $[5,6]$.

In this context it is now known that the $d a / d N$ versus $\Delta K$ relationship associated with the growth of cracks in bridges steels and in the high strength aerospace steels D6ac and 4340 steel are similar and can be represented by the same Nasgro equation $[4,7]$. Furthermore, it is also known that crack growth in bridge steels repaired with an externally bonded composite patch falls on the same "master curve" as does crack growth in operational aircraft and the growth of cracks in aluminum alloys repaired with an externally bonded composite patch [7].

The need to be able to accurately compute the growth of small sub $\mathrm{mm}$ cracks in bridge steels was addressed in [4] which revealed that the crack growth history associated with cracks that arose and grew from natural corrosion in a section of a badly corroded bridge could be predicted as per [8] by using the Nasgro equation for bridge steels, viz:

$$
\frac{d a}{d N}=1.5 \times 10^{-10}\left(\frac{\Delta K-\Delta K_{t p r}}{\sqrt{1-K_{\max } / A}}\right)^{2}
$$

and setting the threshold term $\Delta K_{t b r}$ to a small value, see [4] for more details. Here $A$ is the cyclic fracture toughness, see [4] for more details.

Turning to the question of corrosion and corrosion-fatigue in steel bridges it should be noted that a detailed discussion of the field of corrosion fatigue in steel is provided in [9]. However, there are only a few available publications on the problems of corroded and fatigue in steel bridges. A probabilistic approach which used a damage stress model to predict fatigue lives was developed in [10]. Other methods are focused on the use of S-N curves, which use corrosion rates and cumulative fatigue damage approaches [11,12], for different atmospheric conditions. A fatigue crack growth evaluation method based on linear elastic fracture mechanics was developed in [13]. No available solutions can be found in the literature for the simultaneous effect of material loss due to corrosion and fatigue crack growth due to operational loads.

The prediction of the fatigue life of a corroded bridge steel beam is both difficult and computationally intensive as calculations need to be made at each stage of the life of a beam. This is due to the need to compute the stress intensity factors for each crack configuration; to calculate the amount of crack growth, update the crack geometry, and then recompute the stress intensity factors for this new geometry. This problem was discussed in detail in [8] which presented the fundamental steps needed to compute the crack growth histories associated with naturally occurring cracks in complex geometries subjected to representative operational load spectra. These steps are:

a) Perform a finite element analysis of the uncracked structure.

b) Extract the stresses at the fatigue critical locations

c) Use 3D, or 2D weight functions [14-17], or alternatively Trefftz function solutions [18 -20] to compute the $K(a, c)$ solution space. Here "a" is the crack depth and "c" is the surface crack length. This generally takes less than 5 minutes on a laptop or a PC. Examples of this technique applied to cracking in sideframes, couplers and rail wheels are given in [14, $17]$ and examples associated with cracking in aerospace materials are given in $[8,21]$.

d) Use the Hartman-Schijve variant of the NASGRO together with the $K(a, c)$ solution space determined above and the associated load spectrum to compute the crack length/depth versus cycles history.

However, as explained in [8] when analyzing the more complex problem of the simultaneous occurrence of corrosion and cracks in aging rail bridges the above process needs to be modified to also allow for the reduction in the section thickness as the bridge corrodes. This (unfortunately) means that a range of uncracked models, with different section thicknesses, need to be created and the solution space $K(a, c)$ determined for each. The crack growth analysis then uses the measured (worse case) steady state corrosion rate for the bridge and determines the appropriate $K$ solution from a knowledge of the current crack length and the number of cycles, which are used to determine the amount of material that has been lost, by interpolating between these various solution spaces.

To meet this challenge, this paper will discuss the issues associated with fatigue crack growth in a corroded steel beam. As per the approach outlined in steps a) to d) the first step in the analysis is to create a $3 \mathrm{D}$ model of the steel bridge beam without corrosion and analyze the region of interest. In this initial model, the crack is not explicitly modelled.

Steps b) to c) are then used to determine the stress intensity factors $(K)$ for any given crack length. These stress intensity factors are then used in conjunction with equation (1) to compute the crack growth history, i.e. step d). In this analysis, as outlined in [8], for each increment in crack growth the rate of loss of material due to corrosion is simultaneously computed and adjusted crack length, i.e. after allowing for the associated loss of material, is determined as is the new stress state in the new uncracked section thickness. This process is then continued until failure by either fracture or exceeding the ultimate 
strength of the remaining ligament occurs. The advantage of this approach is that it negates the need to explicitly model cracks, see $[8,14,17]$. A crack of any size can be analyzed using the original (un-cracked) finite element model. As cracks are not modelled explicitly, a coarser mesh can be used to minimize the number of degrees of freedom, thereby reducing the analysis time. Solutions for the stress-intensity factors can then be obtained for a variety of cracks using the original finite element analysis quickly and easily.

To illustrate how this approach can be used to compute the growth of cracks that arise due to natural corrosion in bridge steels a simplified analysis of V/Line Bridge 62 in Kilmore East, Victoria, Australia is performed. By comparing the life obtained by i) allowing only for corrosion and ii) by performing a coupled corrosion-fatigue analysis we find that method i) is very un-conservative. We also show that the interaction between fatigue crack growth and the stress increase created by corrosion induced section reduction needs to be considered when assessing the remaining life of an aged steel bridge.

Having shown how to predict the effect of surface corrosion on the fatigue life of mild steel attention is then focused on the effect of surface roughness on fatigue cracking in Additively manufactured T-6Al-4V. Whilst additive manufacturing (AM) offers the potential to economically fabricate customized parts with complex geometries, the mechanical behavior of these materials must be better understood before AM can be utilized for critical load bearing applications. This is particularly true for aircraft applications where, as detailed in MIL-STD 1530, the design and certification approval require analytical tools that are capable of capturing crack growth and the role of testing is to validate or correct the damage tolerance analysis. To this end it is first shown that the growth of small cracks in a $350 \mathrm{MPa}$ mild steel is similar to the growth of fatigue cracks in both conventionally manufactured Ti-6Al-4V and in in Additively Manufactured LENS (Laser engineered net surface) Ti-6Al-4V. This suggests that the methodology discussed above may also be applicable to study the effect of surface roughness in Additively Manufactured Ti-6Al-4V.

\section{THE AASHTO CORROSION STANDARD}

$\mathrm{B}$ efore we can assess the coupled effect of corrosion and fatigue we first need a knowledge of the rate of corrosion. In this paper we will adopt the American Association of State Highway and Transportation Officials (AASHTO) recommended metal loss model $[22,23]$ which states that the metal loss versus time curve is bi-linear, see Fig. 1. However, as can be seen in Fig. 1, there is little actual data to support this model and the data shown in Fig. 1 is not particularly convincing. This approach to assessing the "steady state" corrosion rate is consistent with the International Standard Corrosion of Metals and Alloys - Corrosivity of Atmospheres, ISO designation 9224 [24], which specifies guiding values of corrosion rate for metals exposed to the atmosphere consisting of an average corrosion rate during the first 10 years of exposure. A detailed review of the corrosion of bridge steels, the AASHTO and ISO corrosion standards and documented steady state corrosion rates associated with a range of locations and steels is in given in [25].

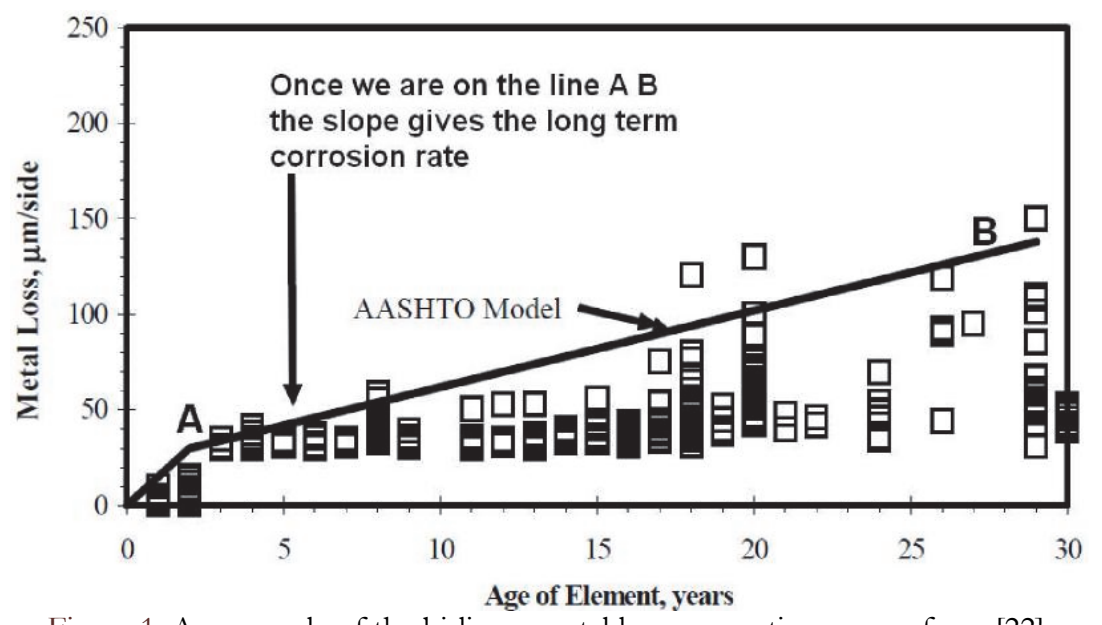

One problem with aging bridges is that if there is any serious corrosion it is likely to have developed over a reasonable number of years. However, to know its significance we need to know how fast the bridge is corroding, i.e. its corrosion rate, at this moment in time. That said you do not have the luxury to locate corrosion sensors or weight loss samples on a 
bridge and wait for a further 5 years or so until the sensors/samples themselves reach the steady state corrosion rate that the bridge is seeing. You need answers much sooner.

The advantage of the AASHTO bi-linear approach is that once the bridge is behaving such that the metal loss versus time curve is on the line $A B$, see Fig.1, you know the long-term corrosion rate without having to monitor the bridge for years. For bridges this can be done in the order of four to twelve months using electrical resistance corrosion sensors [2]. A steel electrical resistance corrosion sensor was used to measure the metal loss in Bridge 62 at Kilmore East which is inland in Victoria, Australia. Fig. 1 substantiates the NCHRP and AASHTO formulation and the advantage gained in real time monitoring of a rail bridge to obtain the long-term corrosion rate. The steady state corrosion rates determined in this test is 0.024 (mm/year). These rates are consistent with those documented in [25].

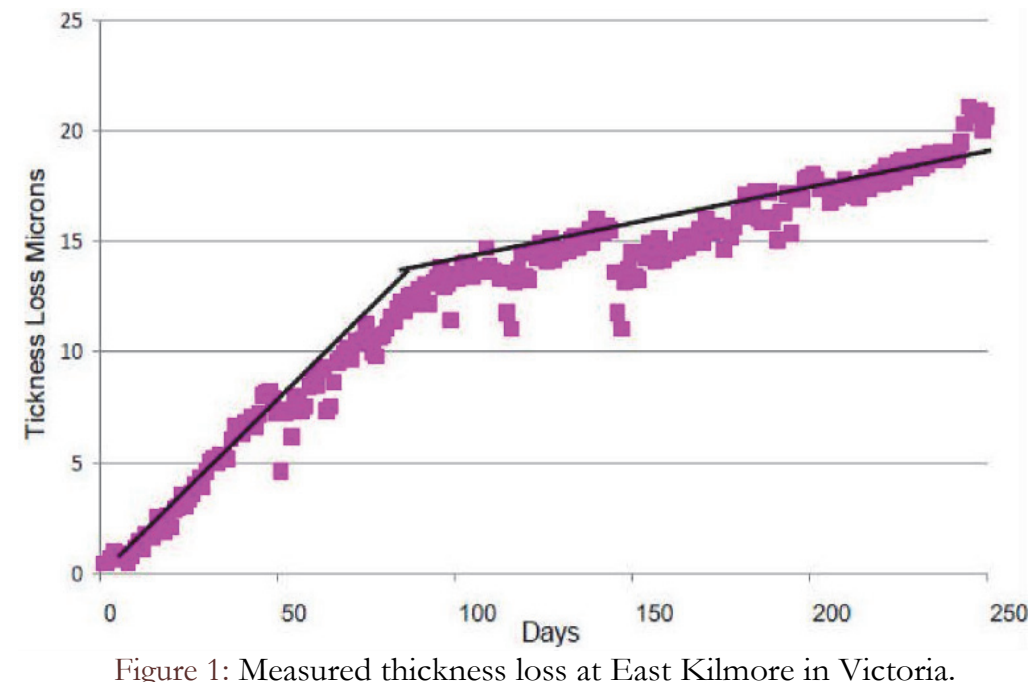

The results of this study support the AASHTO standard for the loss of metal seen by steel bridges. As such the AASHTO bi-linear relationship between metal loss and the time in service provides a simple method for estimating the corrosion rates associated with aging structures.

\section{OPERATIONAL LOAD SPECTRA}

s part of the corrosion measurement program mentioned above the strain (load) spectra was also measured. Bridge A 62 in East Kilmore saw passenger trains, including trains pulled by N Class locomotives, Sprinter carriages, ore 1 trains. Armed with this information and details of the number of trains per week, see Table 1, the load spectrum associated with the bridge can be determined.

\begin{tabular}{llllll}
\hline Train Type & $\begin{array}{l}\text { Loco } \\
\text { Weight }\end{array}$ & $\begin{array}{l}\text { Wagon } \\
\text { Weight }\end{array}$ & $\begin{array}{l}\text { No of } \\
\text { Wagons }\end{array}$ & $\begin{array}{l}\text { No per } \\
\text { Week }\end{array}$ & $\begin{array}{l}\text { Total } \\
\text { Wt/Week }\end{array}$ \\
N Class Passenger & 118 & 60 & 5 & 14 & 5852 \\
Sprinter & & 60 & 2 & 14 & 1680 \\
Ore Train & 128 & 100 & 20 & 7 & 14896 \\
\hline
\end{tabular}

Table 1: Data on trains using UP line over Bridge 62.

\section{FATIGUE CRACK GROWTH WITH CORROSION EFFECT MODEL}

rmed with a knowledge of the $d a / d N$ versus $\Delta K$ behavior of bridge steels, the load spectrum and the steady state corrosion rate we are now in a position to assess the combined effect of corrosion and fatigue on the remaining life of a bridge. 
Failure due to Material loss (Corrosion)

The bending couple $\mathrm{M}$ applied to the section of interest creates normal stresses in the cross section, while the shear force $\mathrm{V}$ creates shearing stresses in that section. Corrosion of steel bridge girders will be a maximum where electrolyte can "wick" between the transom and the girder compression flange or where electrolyte is trapped by some other means. In general, the worst case scenario involves a loss of material from the web, top flange and bottom flange. A graphical representation of the corroded I beam is provided in Figure 3. Using the equation for outer flange fiber stress in beams subject to bending:

$$
\sigma_{Q}=M y / I
$$

where $\sigma$ is the stress, $M$ is the applied Moment, $y$ the distance from the beam neutral axis to the extreme flange fiber and $I$ is the Moment of Inertia about the neutral axis, a spread sheet can be raised which tabulates reducing flange thickness due to corrosion and consequential increased girder flange stresses. The limits are the as-new girder measured stress and the material yield stress.

Let us define the normal and shear stress at point Q1 as shown in Fig. 3 as $\sigma_{Q 1}$ and $\tau_{Q 1}$

$$
\begin{aligned}
& \sigma_{Q 1}=M(y-t) / I \\
& \tau_{Q 1}=(H-t) B t V /(2 b I)
\end{aligned}
$$

With this notation the maximum principle stress at point $\mathrm{Q} 1$ is:

$$
\sigma_{1}\left(Q_{1}\right)=\frac{\sigma_{Q 1}}{2}+\sqrt{\left(\frac{\sigma_{Q 1}}{2}\right)^{2}+\left(\tau_{Q 1}\right)^{2}}
$$

Therefore, the maximum stress in the flange is given by

$$
\sigma=\operatorname{Max}\left[\sigma_{Q}, \sigma_{1}\left(Q_{1}\right)\right]
$$

If the measured corrosion rate for bridge steel I beam is $\xi(\mathrm{mm} /$ year), the maximum stress in I beam $\sigma$ is function of the corrosion rate $\xi$.

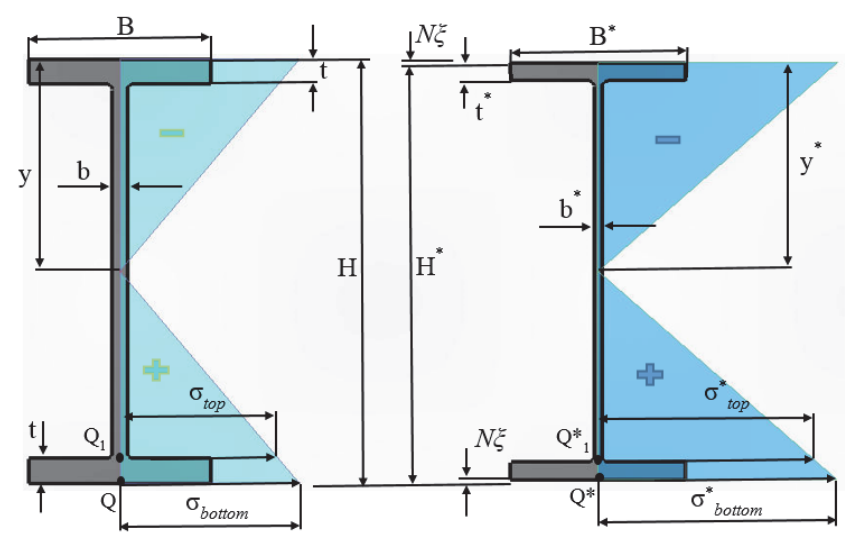

Figure 3: Graphical representation of the corroded I beam.

\section{Failure due to the combined action of corrosion and fatigue}

Since, on tension dominated surfaces, the life of the corroded steel bridge is a strong function of both the corrosion rate and the assumed initiating (inherent) crack size this paper addresses the interaction of combined corrosion and crack growth on remaining life. In this analysis the stress intensity factors were computed as outlined in steps b) and c) in Section 1. For 
each iteration, as the section size reduces, the stress intensity factor for a crack in a corroded steel beam $K_{I}$ can be expressed in the form

$$
K_{I}(a, c)=F_{\sigma} K_{I(\text { original })}\left(a^{*}, c^{*}\right)
$$

where, $F_{\sigma}$ is a "geometry evolution factor" and the stress intensity factor $K_{I(O r i g i n a l)}\left(a^{*}, c^{*}\right)$ is the value with original geometry (there no materials loss due to corrosion) obtained as per $[15,16]$. Here $(a, c)$ and $\left(a^{*}, c^{*}\right)$ denote the crack depths and surface crack lengths without an allowance for the loss of material due to corrosion and allowing for a reduction in the section thickness due to corrosion respectively. The crack depth ' $a$ ' is related $a^{*}$, see Figure 4, by the relationship.

$$
a^{*}=a-\xi t
$$

where $t$ is the current time and $\xi$ is the corrosion rate. If we assume that the crack is a semi-elliptical surface crack the relationship for the surface length can be approximated as

$$
c^{*}=c \sqrt{1-(\xi t / a)^{2}}
$$

If we assume that the rate of corrosion is the same on both the upper and lower surfaces of the beam, then the geometry evolution factor $F_{\sigma}$ can be approximated as:

$$
F_{\sigma}=\frac{\sigma_{b o t t o m}^{*}+\sigma_{t o p}^{*}}{\sigma_{\text {bottom }}+\sigma_{\text {top }}}=\frac{2 y^{*}-t^{*}}{2 y-t} \frac{I}{I^{*}}
$$

Where $I$ and $I^{*}$ are the Moment of Inertia about the neutral axis with original (no corrosion) and the current corroded section respectively.

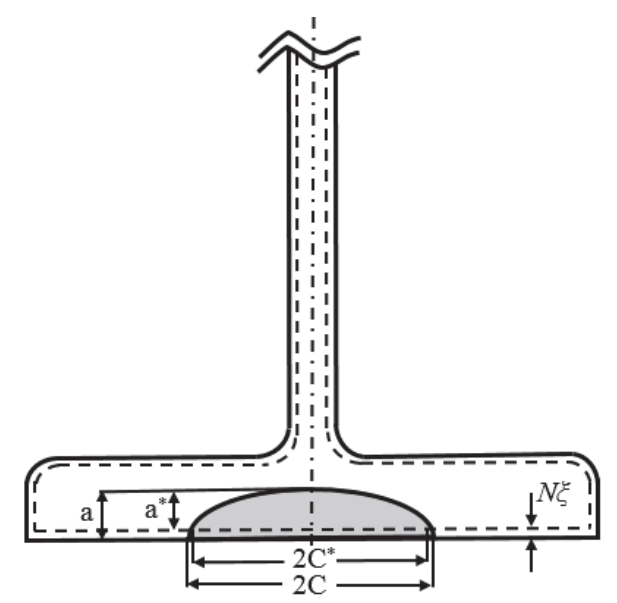

Figure 4: showing a semi-elliptical crack in corroded I beam.

Having determined the current section thickness and the associated stress intensity factors equation (1), i.e. the $d a / d N$ versus $\Delta K$ relationship for bridge steels, is then used to compute the new crack shape. To allow for the simultaneous loss of material due to corrosion both the section thickness and the new crack shape are then modified to account the loss of material due to corrosion. The process is continued until failure either by exceeding the allowable fracture toughness of the material or by exceeding the ultimate strength of the remaining ligament. If the increment in the crack length is less than the loss of material due to corrosion it is assumed that the crack has been "eaten" by the corrosion. In this case the analysis continues using the assumed initial (inherent) crack size input by the user. In this fashion the remaining life of the section can be determined. 


\section{NUMERICAL EXAMPLES AND RESULTS ANALYSIS}

A $\mathrm{n}$ analysis of cracking in Bridge 62 with an assumed corrosion rate of $0.024 \mathrm{~mm} / \mathrm{yr}$ was chosen to illustrate this approach. (This corrosion rate corresponds to the fastest rate measured at the three sites examined in Section 2.) In these initial analyses the initiating (inherent) crack was taken from [4], which tested a section from a condemned and badly corroded steel bridge, to be a $0.05 \mathrm{~mm}$ deep semi-circular initial crack. The sub-structure of this bridge was subjected to significant moisture and resulting corrosion during the wet seasons. The bridge has two rail tracks, each of which is supported by four girders with $4.87 \mathrm{~m}$ length. The dimensions of the girders are given in Tab. 2 .

\begin{tabular}{ll}
\hline Depth & $381 \mathrm{~mm}$ \\
Web thickness & $12 \mathrm{~mm}$ \\
Flange width & $152 \mathrm{~mm}$ \\
Flange thickness & $22 \mathrm{~mm}$ (average) \\
\hline
\end{tabular}

Table 2: Dimensions of the Bridge 62 girders.

The yield stress for this steel was conveyed by V/Line staff to be approximately $240 \mathrm{MPa}$. This implies that retirement resulting from corrosion from an as-new state is approximately 244 years. As mentioned in [28], the deflection requirement of deflection limits of a railway bridge for serviceability limit state under live load plus dynamic load allowance shall be not greater than $1 / 640$ of the span. It is obvious that deflection in this analysis is not a safety issue.

The next stage of this study used the finite element model to compute crack growth. For simplicity the loading applied to model was based on the worse case when an ore train (i.e. one $G$ Class locomotive and 20 fully loaded wagons) transited the bridge. The $\mathrm{G}$ Class locomotive has the following specifications: Total weight $=128$ tons, axle loading $=21.3$ tons, wheel base $=3810 \mathrm{~mm}$, axle spacing $=1905 \mathrm{~mm}$ and leading wheel leading bogie to leading wheel trailing bogie $=12622 \mathrm{~mm}$. Due to symmetry considerations only a quarter of the wheel was modelled. The resultant mesh, which was created using the software program FEMAP [29], had 18,146 twenty-one-noded elements and 91,590 nodes (with a total of 274,770 degrees of freedom). The stresses at critical region were in reasonably good agreement with the results obtained from the field strain gauges measurement presented in Section 3 and discussed in more detail in [30].

In the coupled "corrosion-fatigue" analysis, if the crack growth in a year is less than $0.024 \mathrm{~mm}$, it was assumed that the crack has been "eaten" by corrosion and its length reset to its initial size of $0.05 \mathrm{~mm}$. In this coupled analysis the section thickness continually reduces with time, i.e. as the loss of metal increases, and the stresses increase accordingly. This coupled analysis yielded a life to failure of approximately 81 years. As such there is a difference of $\sim 18 \%$ in the computed fatigue life between the no corrosion and the coupled "corrosion-fatigue" analyses.

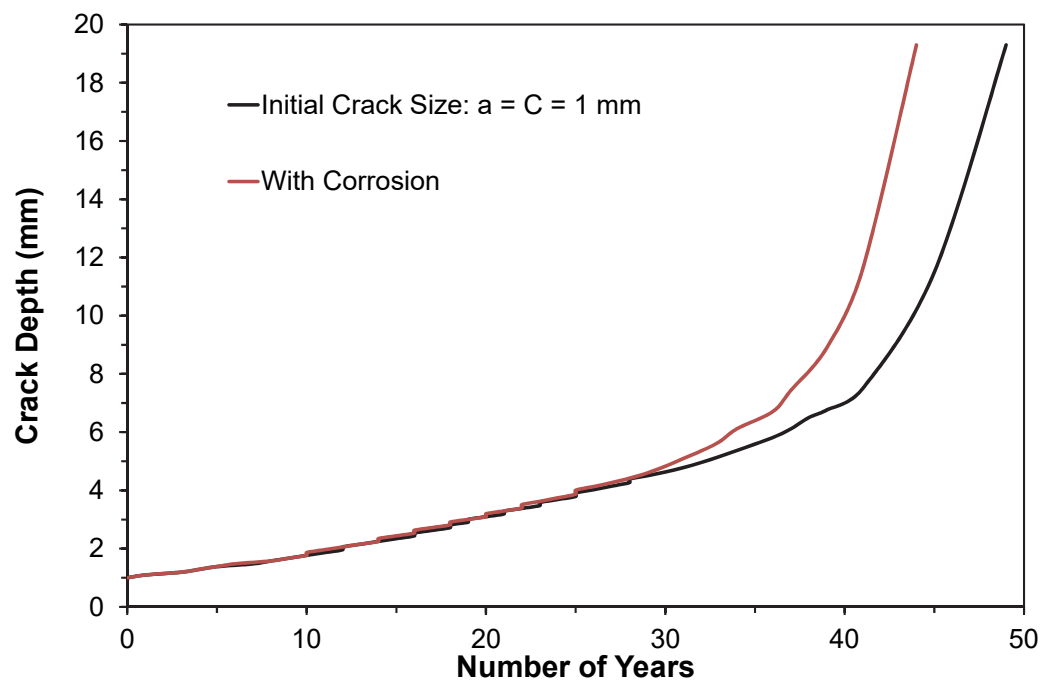

Figure 5: The resultant computed crack growth histories $\left(a_{i}=c_{i}=1 \mathrm{~mm}\right)$. 
It is reported in [4] that the initial crack lengths found in the fatigue test on a specimen cut from a badly corroded bridge varied from approximately $0.1 \mathrm{~mm}$ to $1 \mathrm{~mm}$ [4]. For a $1 \mathrm{~mm}$ initial crack the difference between the two analyses is still significant (approximately 11\%), see Fig. 5.

Since the life of the bridge is a strong function of the size of the initiating (inherent) defect, the analysis was repeated for a range of initial crack sizes and the resulting lives are shown in Fig. 6. This analysis revealed that the percentage difference between the case of no corrosion and the coupled "corrosion-fatigue" analysis reduces as the size of initial (inherent) crack is increased.

Remaining Bridge Life viz. Initial Flaw Size

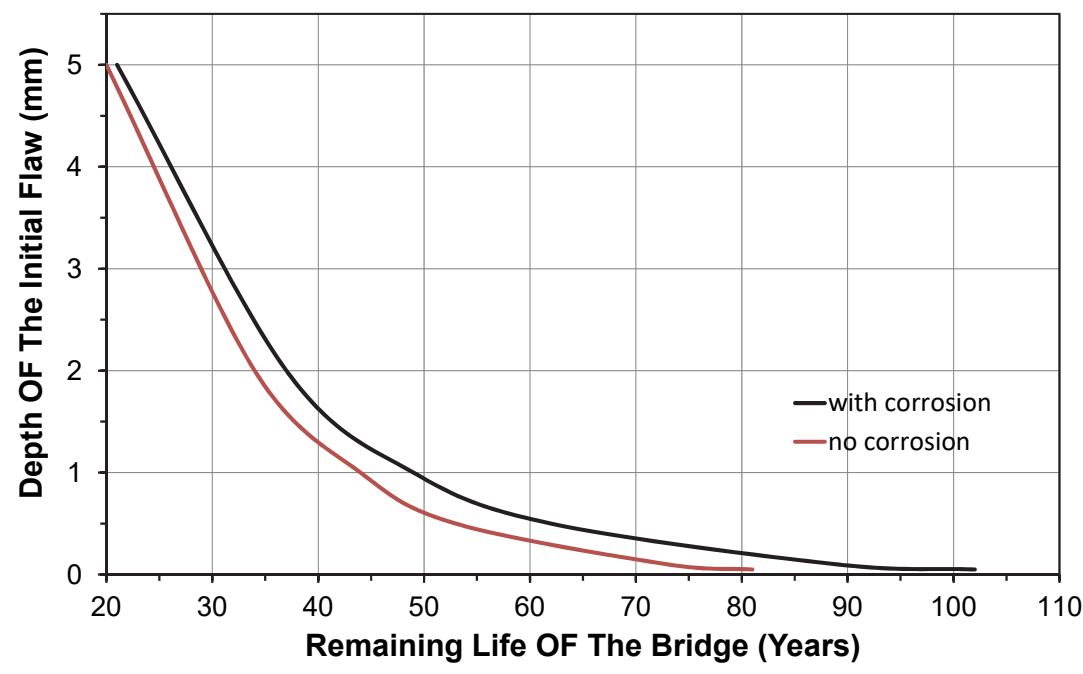

Figure 6: Effect of the depth of the crevice on the remaining life of the bridge.

\section{IMPLICATIONS FOR ADDITIVELY MANUFACTURED STRUCTURES}

7 he work presented above has dealt with cracks that have arisen naturally and subsequently grown from rough, in this instance corroded, surfaces in a $350 \mathrm{MPa}$ mild steel. However, let us now turn our attention to the effect of surface roughness in Additively Manufactured Ti-6Al-4V. In this context the review paper [31] noted that whilst additive manufacturing (AM) offers the potential to economically fabricate customized parts with complex geometries, the mechanical behavior of these materials must be better understood before AM can be utilized for critical load bearing applications. This is particularly true for cracks in aircraft applications where, as detailed in MIL-STD 1530 [32], the design and certification approval require analytical tools that are capable of capturing crack growth and the role of testing is to validate or correct the damage tolerance analysis.

Berto et al [33-36], Kahlin, Ansell and Moverare [37, 38], Greitemeier et al [39], Chan [40] and Leuders et al [41] each revealed that the rough surfaces associated with as additively manufactured parts significantly degrade the fatigue performance of AM structures. The sentence used in [37] was: "The surface roughness is the single most severe factor for fatigue for additive manufactured materials". The importance of characterizing the material discontinuities, including surface roughness, associated with AM materials is also stressed in [33, 32, 42]. Indeed, [42] suggested that, as we have seen in the previous section, the surface roughness of the material can be treated in the same way as short cracks. The present paper therefore suggests that the methodology outlined above has the potential to study the growth of small naturally occurring cracks that arise and grow form rough surfaces in Additively Manufactured Ti-6Al-4V. This hypothesis is supported by the fact that the $d a / d N$ versus $\Delta \mathrm{K}$ curves associated with the growth of small cracks in a $350 \mathrm{MPa}$ mild steel [43] is similar to the growth of fatigue cracks in both conventionally manufactured Ti-6Al-4V and in in Additively Manufactured LENS (Laser engineered net surface) Ti-6Al-4V.

To illustrate this Figure 13 presents the $d a / d N$ versus $\Delta K$ curves associated with the growth of small cracks in a $350 \mathrm{MPa}$ mild steel [43], which were tested at a range of $R$ ratios, together with:

i) the $R=0.1$ short crack curve for Mill Annealed Ti-6Al-4V [44],

ii) the small crack $d a / d N$ versus $\Delta K$ curve for the growth of small cracks in Additively Manufactured LENS (Laser engineered net surface) Ti-6Al-4V [45]. 
iii) the small crack $d a / d N$ versus $\Delta K$ curve for the growth of small cracks in the aerospace quality titanium alloys Ti-6246 [46] and Ti-17 [47].

As can be seen in Fig. 7 despite the differences in micro-structures and chemical composition the small crack curves associated with crack growth in the various Titaniums, LENS Ti-6Al-4V and the $350 \mathrm{MPa}$ grade mild steel are in good agreement. As a result, it is hypothesized that the methodology outlined above has the potential to study the growth of small naturally occurring cracks that arise and grow form rough surfaces in Additively Manufactured Ti-6Al-4V.

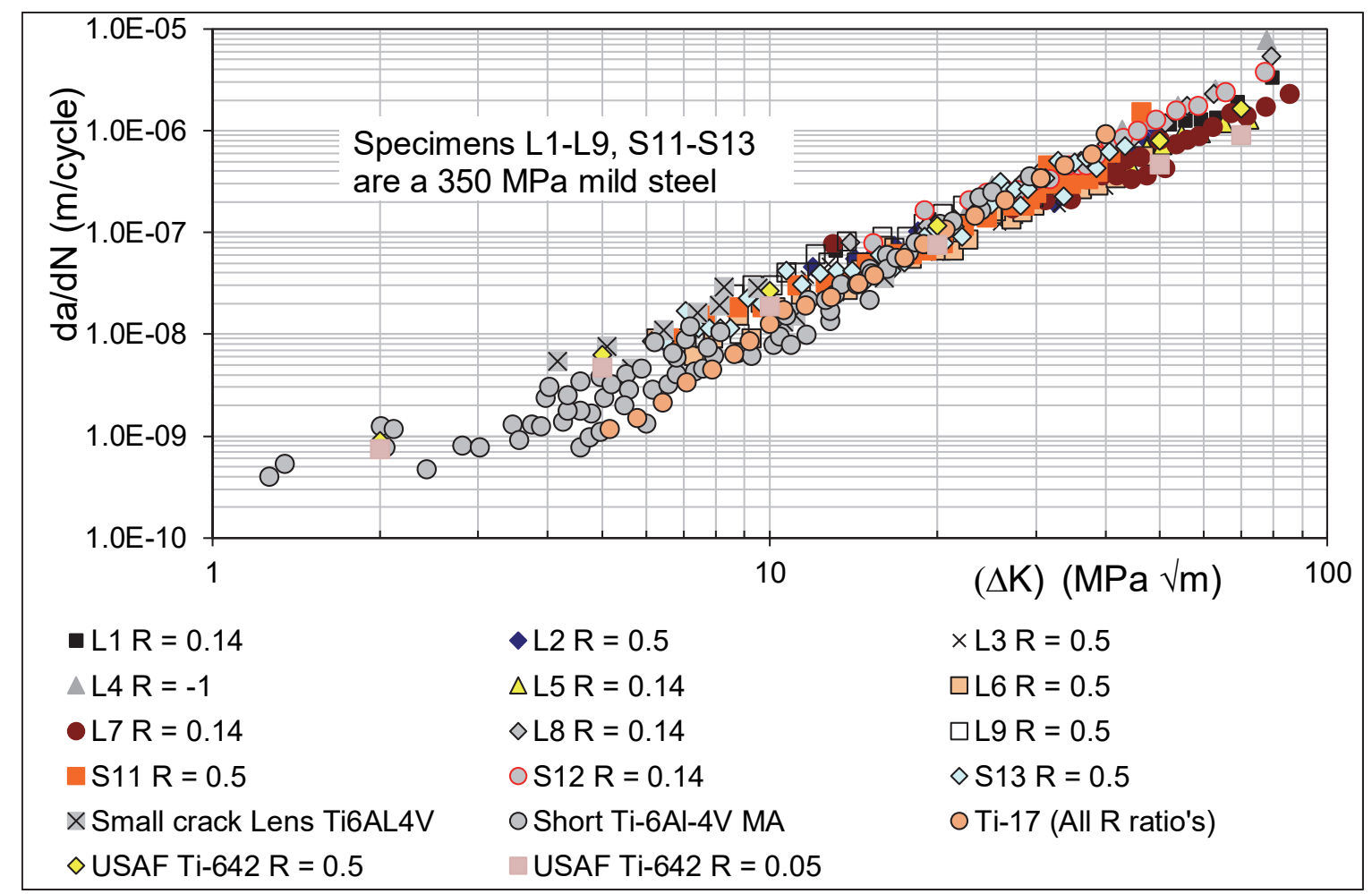

Figure 7: Comparison of cracking in a $350 \mathrm{MPa}$ mild steel with cracking in a range of titanium alloys.

As an important factor in failure assessments under fatigue and static loading, 3D effect has been studied in numerous researches and 3D effects in the form of stress state have been investigated for wide variety of notch geometries under various in-plane and out of plane loading conditions by considering stress concentration factors and constraint factors throughout the thickness of the specimen [48,49]. As a representative of stress state in cracked and notched components, the variations of the stress concentration factor as a function of the thickness have been studied in some recent researches by Berto and co-researchers [50-56]. As an interesting and effective fact, the same concept can be considered for fatigue crack growth assessment in metallic components of steel bridges with presence of natural corrosion in the material.

\section{CONCLUSIONS}

7 his paper has presented a methodology that can be used to compute the growth of cracks that arise due to natural corrosion in bridge steels. A simplified analysis of V/Line Bridge 62 has been used to illustrate the need to perform a coupled corrosion-fatigue analysis. Furthermore, comparing the life obtained by allowing only for corrosion and by performing a coupled corrosion-fatigue analysis we find that:

a. Life allowing for corrosion only $=244$ years

b. Life allowing for the coupled effect of corrosion and fatigue $=81$ years

Therefore, failure as a result of metal loss from only corrosion would appear to be un-conservative. As such the interaction between fatigue crack growth and the stress increase created by corrosion induced section reduction must be considered when assessing the remaining life of steel bridges. We also raise the possibility that the methodology may also be applicable to assessing the effect of surface roughness on additively manufactured parts. 


\section{REFERENCES}

[1] The Fix We're In For: The State of Our Nation's Busiest Bridges, Transportation For America//October 2011. Available on line at: http://t4america.org/docs/bridgereport/bridgereport-metros.pdf.

[2] Connor, R. J., Dexter, R and Mahmoud, H. (2005). Inspection and Management of Bridges with Fracture-Critical Details: A Synthesis of Highway Practice, National Cooperative Highway Research Program, NCHRP Synthesis 354, Transportation Research Board, Washington, D.C.

[3] Mertz, D. (2012). Steel Bridge Design Handbook: Design for Fatigue, U.S. Department of Transportation, Federal Highway Administration, Publication No. FHWA-IF-12-052 - Vol. 12.

[4] Ali, K., Peng, D., Jones, R., Singh, R. R. K., Zhao, X. L., McMillan, A. J. and Berto, F. (2017). Crack growth in a naturally corroded bridge steel. Fatigue \& Fracture of Engineering Materials \& Structures, 40(7), pp. 1117-1127.

[5] Berens, A. P., Hovey, P. W. and Skinn, D. A. (1991). Risk analysis for aging aircraft fleets - Volume 1: Analysis, WL-TR-913066, Flight Dynamics Directorate, Wright Laboratory, Air Force Systems Command, Wright-Patterson Air Force Base.

[6] Barter, S. A., Molent, L. and Wanhill, R. H. (2012). The lead crack lifing framework. International Journal of Fatigue, 41, pp. 1-198.

[7] Ali, K., Singh, R. R. K., Zhao, X. L., Jones, R. and McMillan, A. J. (2017). Composite repairs to bridge steels demystified. Journal of Composite Structures, 169, pp. 180-189.

[8] Jones, R. (2014). Fatigue crack growth and damage tolerance. Fatigue and Fracture of Engineering Materials and Structures, 37, pp. 463-483.

[9] Akid, R., Richardson, T. ed., (2010). Corrosion Fatigue. In Shreir's Corrosion. Vol. 2, pp. 928-953.

[10] Adasooriya, N. D. (2016). Fatigue reliability assessment of ageing railway truss bridges: Rationality of probabilistic stress-life approach. Case Studies in Structural Engineering, 6, pp. 1-10.

[11] Adasooriya, N. D. and Siriwardane, S. C. (2014). Remaining fatigue life estimation of corroded bridge members. Fatigue and Fracture of Engineering Materials and Structures, 37, pp. 603-622.

[12] Wanninayake, W.T.M.S.M., Wasala, W.M.P.R. and Bandara, C.S. (2015). Life evaluation of critical members of steel bridges located in different atmospheres, Proceedings of the $6^{\text {th }}$ International Conference on Structural Engineering and Construction Management, Kondy, Sri Lonko.

[13] Zhou, T. Q., Chan, T. H. T. and Hua, Y. (2006). Fatigue Damage Analysis on Crack Growth and Fatigue Life of Welded Bridge Members with Initial Crack, Key Engineering Materials, ISSN: 1662-9795, Vols. 324-325, pp 251-254.

[14] Peng, D., Jones, R., Constable, T., Lingamanaik, S. N. and Chen, B. K. (2012). The tool for assessing the damage tolerance of railway wheel under service conditions. Theoretical and Applied Fracture Mechanics, 57, 1-13.

[15] Jones, R., Peng, D., Pitt, S. and Wallbrink, C. (2004). Weight Functions, CTOD, and Related Solutions for Cracks at Notches. Engineering Failure Analysis, 11, pp. 79-36.

[16] Peng, D., Wallbrink, C. and Jones, R. (2005). Stress intensity factor solutions for finite body with quarter-elliptical flaws emanating from a notch. Engineering Fracture Mechanics, 72(9), pp. 1329-1343.

[17] Peng, D., Jones, R. and Constable, T. (2013). Tools and methods for addressing the durability of rolling stock. Engineering Failure Analysis, 34, pp. 278-289.

[18] Pitt, S., Jones, R. and Atluri, S. N. (1999). Further studies into interacting 3D cracks. Computers and Structures, 70, pp 583-597.

[19] Pitt, S. and Jones, R. (1997). Multiple-Site and Widespread Fatigue Damage in Aging Aircraft. Engineering Failure Analysis, 4, pp. 237-257.

[20] Vijayakumar, K. and Atluri, S. N. (1981). Embedded elliptical crack in an infinite solid, subject to arbitrary crack-face tractions. Journal of Applied Mechanics, Transactions ASME, 48(1), pp. 88-96.

[21] Peng, D., Jones, R., Lo, M., Bowler, A., Brick, G., Janardhana, M. and Edwards, D. (2015). Crack growth at fastener holes containing intergranular cracking. Engineering Fracture Mechanics, 137, pp. 79-87.

[22] Fishman, K. L. and Withiam, J. L. (2011). LRFD Metal Loss and Service-Life Strength Reduction Factors for MetalReinforced Systems, NCHRP 675, Transportation Research Board, Washington, DC.

[23] AASHTO, 2009, LRFD Bridge Design Specifications, 4th Ed. With Interims, American Association of State Highway and Transportation Officials, Washington, D.C. 
[24] ISO 9224:2012: Corrosion of metals and alloys - Corrosivity of atmospheres - Guiding values for the corrosivity categories. Published in Switzerland.

[25] Albrecht, P. and Hall, Jr. T. T. (2003). Atmospheric Corrosion Resistance of Structural Steels. Journal of Materials In Civil Engineering, 15, pp. 1-24.

[26] Wade, S. A., Begbie, K. J. and Trueman, A. (2007). Measuring atmospheric corrosion of industrial infrastructure using electrical resistance corrosion sensors, presented at the Corrosion Control 007, Australasian Corrosion Association, Sydney, paper 118 .

[27] Elston, J., Peng, D., Baker, J., Cairns, K., Pitt, S. and Thilakarathna, H. (2012). Development of Inspection and User Friendly Monitoring Program for BMS - Deliverables arisen from Facet 5, Project Title: Life Cycle Management of Railway Bridges Project Code: R3.118, CRC for Rail Innovation Report.

[28] Bridge Design Australian Standard, AS 5100.2-2004.

[29] FEMAP - Finite Element Modelling and Post Processing, Version 11.1.2, Structural Dynamics Research Corporation, Pennsylvania; 2015.

[30] Peng, D. and Cairns, K. (2012). Bridge 62 near Kilmore East Strain Gauge Data Analysis, Rail CRC report, Monash University.

[31] Li, P., Warner, D. H., Fatemi, A. and Phan, N. (2016). Critical assessment of the fatigue performance of additively manufactured Ti-6Al-4V and perspective for future research. International Journal of Fatigue, 85, pp. 130-143.

[32] MIL-STD-1530D, Department Of Defense Standard Practice: Aircraft Structural Integrity Program (ASIP) (31-Aug2016).

[33] Razavi, S. M. J., Ferro, P. and Berto, F. (2017). Fatigue assessment of Ti-6Al-4V circular notched specimens produced by Selective Laser Melting. Metals. 7(8), pp. 291.

[34] Razavi, S. M. J., Ferro, P., Berto, F. and Torgersen, J. (in press). Fatigue strength of blunt V-notched specimens produced by Selective Laser Melting of Ti-6Al-4V. Theoretical and Applied Fracture Mechanics. (DOI: 10.1016/j.tafmec.2017.06.021)

[35] Branco, R., Costa, J. D., Berto, F., Razavi, S. M. J., Martins Ferreira, J. A., Capela, C., Santos, L. and Antunes, F. (2018). Low-cycle fatigue behaviour of sintered AISI 18Ni300 maraging steel produced by selective laser melting. Metals, 8(1), pp. 32.

[36] Razavi, S. M. J., Bordonaro, G. G., Ferro, P., Torgersen, J. and Berto, F. (2018). Fatigue behavior of porous Ti-6Al-4V made by Laser Engineered Net Shaping. Materials, 11(2), pp. 284.

[37] Kahlin, M., Ansell, H. and Moverare, J. J. (2017). Fatigue behaviour of notched additive manufactured Ti6Al4V with as-built surfaces. International Journal of Fatigue, 101, pp. 51-60.

[38] Kahlin, M., Ansell, H. and Moverare, J. J. (2017). Fatigue behaviour of additive manufactured Ti6Al4V, with as-built surfaces, exposed to variable amplitude loading. International Journal of Fatigue, 103, pp. 352-363.

[39] Greitemeier, D., Donne, C. D., Syassen, F., Eufinger, J. and Melz, T. (2016). Effect of surface roughness on fatigue performance of additive manufactured Ti-6Al-4V. Materials Science and Technology, 32(7), pp. 629-634.

[40] Chan, K. S. (2015). Characterization and analysis of surface notches on Ti-alloy plates fabricated by additive manufacturing techniques. Surface Topography: Metrology and Properties, 3(4). (DOI:10.1088/2051$672 \mathrm{X} / 3 / 4 / 044006)$

[41] Leuders, S., Vollmer, M., Brenne, F., Troster, T. and Niendorf, T. (2015). Fatigue Strength Prediction for Titanium Alloy TiAl6V4 Manufactured by Selective Laser Melting. Metallurgical and Materials Transactions A, 46(9), pp. 38163823.

[42] Grelik, M. (2017). Additive manufacturing in the context of structural integrity. International Journal of Fatigue, 94, pp. 168-177.

[43] Jones, R., Singh Raman, R. K. and McMillan, A. J. (2018). Crack growth: Does microstructure play a role?. Engineering Fracture Mechanics, 187, pp. 190-210.

[44] Wang, K., Wang, F., Cui, W., Hayat, T. and Ahmad, B. (2014). Prediction of short fatigue crack growth of Ti-6Al-4V. Fatigue \& Fracture of Engineering Materials \& Structures, 37, pp. 1075-1086.

[45] Sandgren, H. R., Zhai, Y., Lados, D. A., Shade, P. A., Schuren, J. C., Groeber, M. A., Kenesei, P. and Gavras, A. G. (2016). Characterization of fatigue crack growth behavior in LENS fabricated Ti-6Al-4V using high-energy synchrotron x-ray microtomography. Additive Manufacturing, 12, pp. 132-141.

[46] Jha, S. K., John, R. and Larsen, J. M. (2013). Incorporating small fatigue crack growth in probabilistic life prediction: Effect of stress ratio in Ti-6Al-2Sn-4Zr-6Mo. International Journal of Fatigue, 51, pp. 83-95.

[47] Cadario, A. and Alfredsson, B. (2007). Fatigue growth of short cracks in Ti-17: Experiments and simulations. Engineering Fracture Mechanics, 74, pp. 2293-2310. 
[48] Kotousov, A., Lazzarin, P., Berto and F., Pook, L. (2013). Three-dimensional stress states at crack tip induced by shear and anti-plane loading. Engineering Fracture Mechanics, 108, pp. 65-74.

[49] Kotousov, A., Berto, F., Lazzarin, P. and Pegorin F. (2012). Three dimensional finite element mixed fracture mode under anti-plane loading of a crack. Theoretical and Applied Fracture Mechanics, 62, pp. 26-33.

[50] Campagnolo, A., Berto, F. and Lazzarin, P. (2015). The effects of different boundary conditions on three-dimensional cracked discs under anti-plane loading, European Journal of Mechanics-A/Solids, 50, 76-86.

[51] Berto, F. and Marangon, C. (2013). Three-dimensional effects in finite thickness plates weakened by rounded notches and holes under in-plane shear. Fatigue \& Fracture of Engineering Materials \& Structures, 36(11), pp. 1139-1152.

[52] Marangon, C., Campagnolo, A. and Berto, F. (2015). Three-dimensional effects at the tip of rounded notches subjected to mode-I loading under cyclic plasticity. The Journal of Strain Analysis for Engineering Design, 50(5), pp. $299-313$.

[53] He, Z., Kotousov, A., Berto, F. and Branco, R. (2016). A brief review of recent three-dimensional studies of brittle fracture. Physical Mesomechanics, 19(1), 6-20.

[54] Berto, F., Lazzarin, P., Kotousov, A. and Pook, L. (2012). Induced out-of-plane mode at the tip of blunt lateral notches and holes under in-plane shear loading. Fatigue and Fracture of Engineering Materials and Structures, 35, pp. 538-55.

[55] Berto, F., Kotousov, A., Lazzarin, P. and Pook, L. (2013). On scale effect in plates weakened by rounded V-notches and subjected to in-plane shear loading. International Journal of Fracture, 180, pp. 111-118.

[56] Pook, L. P., Campagnolo, A., Berto, F. and Lazzarin, P. (2015). Coupled fracture mode of a cracked plate under antiplane loading. Engineering Fracture Mechanics, 134, pp. 391-403. 